\title{
Effects of Perceived Social Support and Psychological Resilience on Social Media Addiction among University Students
}

\author{
Okan Bilgin ${ }^{1}$, İbrahim Taş ${ }^{2, *}$ \\ ${ }^{1}$ Department of Educational Sciences, Bulent Ecevit University, Turkey \\ ${ }^{2}$ Department of Educational Sciences, Istanbul Sabahattin Zaim University, Turkey
}

Copyright $\bigcirc 2018$ by authors, all rights reserved. Authors agree that this article remains permanently open access under the terms of the Creative Commons Attribution License 4.0 International License

\begin{abstract}
This research investigated the effects of perceived social support and psychological resilience on social media addiction among university students. The research group was composed of 503 university students. The ages of participant students varied between 17 and 31 years old. $340(67.6 \%)$ of the participants are female and $163(32.4 \%)$ of them are male. The Personal Information Form, Perceived Social Support Scale, Psychological Resilience Scale, and Social Media Addiction Scale were used as data collection instruments. The data obtained were analyzed with the Pearson's correlation and hierarchic regression. Negative relationship was observed between perceived social support and social media addiction and between psychological resilience and social media addiction. Furthermore, it was found that perceived social support significantly predicted the subscale of perceived social support from friends and psychological resilience was a significantly predictor of social media addiction. The findings were discussed in the light of the related literature.
\end{abstract}

Keywords Social Media Addiction, Social Support, Psychological Resilience

\section{Introduction}

Having entered our lives as a communication tool, Internet has somehow changed dimensions and sustained its presence in several fields. One of those fields is social media. People meet not only their needs for communication but also other needs such as entertainment, socialization, liking and being liked.

Social networking websites are web-based sites of which limits are designated by the system, which are open or semi-open to public and in which people have a list of contacts to share any link with, link lists and shared links are displayed and get into circulation [1]. In short, social networking websites can be defined as virtual communities where everyone can create profiles open to anyone [2]. These virtual communities offer their users the opportunity to communicate with their friends in the social life or at school and individuals which they share a common interest with [3].

Since its first example established in 1997, social networking websites have greatly diversified. Whereas some websites address any group, others target their users through a common language, culture, sexual preference, religion and national identities [1].

Individual-centered structure of social networking sites is a quite effective feature that attracts people to social networks [2]. Used very commonly for this feature, social networking websites present risk more than most of the people think. Some of the risks include peer-to-peer risks, risks regarding inappropriate contents, and risks of breaching the online confidentiality [3].

Social networks provide individuals with the chance to present themselves positively and make their moods more positive. The desire to maintain this positive mood or make it constant leads to the addictive behavior for social media [2]. As a result, individuals can experience problems that seriously affect their lives. Social media addiction can be handled as a psychological problem which develops in three processes that are cognitive, affective and behavioral and disrupts individual's functionality in his/her private life, working life and social life through problems like mood dysregulation and conflict [4]. There is no clear definition of social media addiction, which makes it difficult for studies to be conducted in the related field [5].

Criteria used in the definitions of social media addiction have changed in time. Three criteria of mind constantly preoccupied by social media, loss of control and withdrawal which were used in the first definitions were increased up to six criteria by Andreassen, Torsheim, Brunborg and Pallese [6] as mood modification, being behaviorally, cognitively and emotionally preoccupied by 
social media use, tolerance, withdrawal symptoms, conflict and relapse. Finally, based on the diagnostic criteria of Internet gaming addiction in DSM V once it was published, social media addiction started to be addressed through nine criteria with the addition of lying about the time spend on social media, having problems due to intensive use, failing to quite despite the will to quit and replacing it with others to be done [5].

Lack of a clear definition of social media addiction limits research in the literature. Nevertheless, an increase is observed in the studies on social media addiction in the literature in recent years. It was found in the study performed by Tektaş [7] that $80 \%$ of the university students spent 1 hour or above on social media. The studies in the literature found social media addiction positively related to frequency of Internet use [7], loneliness [8], duration of social media use [4], extraversion, openness, emotional problems, anxiety [9], Facebook gaming addiction [10], number of friends, narcissism [11] and usage for education, social relations, communication and cooperation [12] and negatively related to personal relations with the surrounding [13], satisfaction with life [9], and self-esteem [14]. As well as studies conducted with gender which showed that social media addiction was more prevalent among women [7], there are other studies that it was more prevalent among men [4][12].

Described as all kinds of support procured by individuals from others for coping with stressful life events [15], social support is an important indicator that an individual is loved, liked, respected and valued (Cobb, 1976, p. 300 in [16]). Social support refers to social networks, social resources and social assets from which an individual receives help, support, recommendation and approval, consolation, and protection [17]. Social support, as a supportive force in an individual's life, can be obtained from many different sources.

Social support resources include family and relatives, friends, opposite sex, teachers, colleagues, neighbors, and ideological and religious groups or ethnic groups [18]. Besides social supports' direct relationship with being healthy and feeling good, it is effective in reducing the impact of stressful life events [19]. People who are social entities call people to support them when they have psychological problems. As natural supportive resources, social support resources play a role in facilitating the solution of psychological problems [20].

In the research studies on perceived social support in the literature, perceived social support and its subscales were found positive significantly related to psychological well-being and psychological resilience [21], psychological well-being [22], forgiveness of self and situations [23], self-esteem [24] and perceived social support was found negative significantly related to loneliness [25]; [26], problematic Internet use [27], parental recognition-rejection [23], and constant anger [24]. While some studies addressing the perceived social support by the gender variable showed that perceived social support was significantly high among men [28]; [19], others concluded that it was significantly higher among girls [29]. There are also studies concluding that perceived social support did not differ significantly [30]; [22]; [31]. As can be seen from the results of the researches, social support has a very important place in the life of the individuals.

Some people can quickly recover and get back to their normal lives and adapt to their new lives after stressful events, traumas and other challenging life events while some might experience long-term psychological problems and it might take time for them to go back to their normal lives and adapt to the new situation.

The concept of psychological resilience investigated in several fields such as psychology, psychiatry, sociology, neuroscience [32] can be defined as the ability to overcome a negative experience successfully and adapt to the consequent new life conditions [33]. The concept refers not to a behavior or a trait of an individual in a given field but his/her general characteristic [34]. Psychological resilience emerges as a product of the interaction between seriously risky experiences and relatively positive psychological experiences [35].

There are several factors that affect psychological resilience. Personality traits of openness, extraversion, adaptability; locus of internal control, resourcefulness, self-efficacy, optimism; positive and cognitive interpretation of events; and social support from family and friends are some of the elements that affect psychological resilience [32]. Psychological resilience, which is influenced by many factors, provides advantages for individuals without coping with the difficulties of individuals' lives. From this point it is important to know the concepts related to psychological resilience.

The studies conducted on psychological resilience in the literature showed that psychological resilience was positively related to adaptation to university [36], social connectedness and recognition about belonging [37], secure attachment [38], forgiveness of self, others and situations [39], satisfaction with life [40], optimism and psychological well-being [41], happiness [33], positive self-schema [42], emotional intelligence [43], and self-esteem and positive emotions [44] and negatively related to psychological symptoms [36], psychological abuse and rejection about belonging [37], fearful attachment and anxious attachment [38], depression [45], locus of control and negative emotions [44], and psychological disorders [46].

No study investigating the relationship between social media addiction and perceived social support and psychological resilience among university students was observed in the literature. Perceived social support and psychological resilience's positive impact on individual's mental health makes it important to investigate how these concepts are related to social media addiction which is a negative behavior. Lack of any study on these concepts in the literature also makes this study important. In this 
context, answers to the following questions were sought for in the study:

Is there a relationship between social support and psychological resilience and social media addiction?

Do perceived social support and psychological resilience predicts social media addiction?

\section{Method}

\subsection{Research Model}

The survey model was used in this study which investigated the relationship between social media addiction and perceived social support and psychological resilience among university students. Since the relationship between two or more variables was examined without any intervention [47], this can be considered a correlational research.

\subsection{Research Group}

The research group was composed of 503 university students studying at Bülent Ecevit University Ereğli Faculty of Education. The ages of participant students varied between 17 and 31 years old. $340(67.6 \%)$ of the participants are female, $163(32.4 \%)$ of them are male. 116 (23.1\%) of the students were in the first grade, 147 (29.2\%) were in the second grade, $170(33.8 \%)$ were in the third grade, and $70(13.9 \%)$ were in the fourth grade.

\subsection{Data Collection Instruments}

\subsubsection{Personal Information Form}

Socio-demographics of the participant students were obtained through the personal information form prepared by the researcher.

\subsubsection{Social Media Addiction Scale}

The Social Media Addiction Scale - Adult Form (SMAS-AF) was developed by Şahin and Yağc1 [48]. The 5-point Likert-type scale comprises of two subscales (virtual communication and virtual tolerance) and 20 items. Higher total scores in the scale mean social media addiction. The factor loads of the scale vary between .61 and .87. Fit indexes of the scale are RMSA $=.059$, $\mathrm{SRMR}=.060, \mathrm{NFI}=.59, \mathrm{CFI}=.96, \mathrm{GFI}=.90$, and $\mathrm{AGFI}=.88$ respectively. Its Chi-square value $=7051,32$, $s d=190$, $\mathrm{p}=0.00$. Cronbach's Alpha internal consistency coefficients were calculated to be .94 for the scale, .92 for virtual tolerance and .91 for virtual communication. The test-retest reliability coefficients were found .93 for the scale, .91 for virtual tolerance, and .90 for virtual communication.

\subsubsection{Perceived Social Support Scale}

The Multi-Dimensional Scale of Perceived Social
Support (MDSPSS) was developed by Zimmet et al. [49] and adapted into Turkish language by Eker and Akar (1995). It was later reviewed and finalized by Eker, Arkar and Yaldiz [20]. The 7-point Likert-type scale is composed of 12 items and three subscales: perceived social support from family, perceived social support from friends, and perceived social support from a special person. Cronbach's Alpha value of the scale was found .89. Internal consistency coefficients were found .85 for perceived social support from family, .88 for perceived social support from friends, and .92 for perceived social support from a special person. Principal component factor analysis was performed to determine the structure validity of the scale, and it was seen that 12 items were in related 3 factors of which eigenvalue was above 1 and it explained $75 \%$ of the total variance.

\subsubsection{Psychological Resilience Scale}

The Brief Psychological Resilience Scale was developed by Smith et al. and adapted into Turkish language by Doğan [33]. The 5-point Likert-type is composed of 6 items and one subscale. Higher scores obtained in the scale refer to psychological resilience. It was found that corrected item-total correlation values of the item analysis varied between .49 and .66 . In the confirmatory factor analysis, goodness of fit indexes were found $\chi^{2} / \mathrm{sd}(12.86 / 7)$ $=1.83, \quad \mathrm{NFI}=0.99, \quad \mathrm{NNFI}=0.99, \quad \mathrm{CFI}=0.99, \quad \mathrm{IFI}=0.99$, RFI $=0.97$, GFI $=0.99, \quad$ AGFI $=0.96, \quad$ RMSEA $=0.05$, and $\mathrm{SRMR}=0.03$. Internal consistency coefficient of the scale was found .83. Correlation results regarding the criterion related validity $(\mathrm{r}=.40$ with Oxford Happiness Scale, $\mathrm{r}=.66$ with Connor-Davidson Psychological Resilience Scale, and $\mathrm{r}=.61$ with Ego-Resiliency Scale) showed that the scale is valid.

\subsection{Collection and Analysis of the Data}

The research data were obtained in one-on-one applications with the university students. The data were analyzed after the application, and the incomplete forms were excluded from the dataset. So, number of subjects was downed from 520 to 503 . Next, the relationships between the variables were analyzed with Pearson's correlation analysis. Hierarchic regression analysis was also performed to predict the dependent variable. Perceived social support from family, perceived social support from a special person and perceived social support from friends were included in the analysis in the first step. Psychological resilience was included in the second step. SPSS 22 software package was used in the data analysis.

\section{Findings}

Kurtosis and skewness values of the data were calculated to determine whether the data were normally distributed before the data analysis, and the results are shown in Table 1. 
Table 1. Skewness and Kurtosis Values of the Dependent and Independent Variables

\begin{tabular}{|c|c|c|c|c|c|}
\hline & $\mathrm{N}$ & $\bar{X}$ & $\mathrm{Sd}$ & Skewness & Kurtosis \\
\hline SMAT & 503 & 49.956 & 11.651 & .25 & .32 \\
\hline SMAVT & 503 & 28.501 & 6.383 & .109 & .027 \\
\hline SMAVC & 503 & 21.455 & 6.360 & .400 & .514 \\
\hline PSSF & 503 & 24.051 & 5.237 & -1.58 & -.513 \\
\hline PSSSP & 503 & 19.316 & 8.851 & -1.34 & .893 \\
\hline PSSFR & 503 & 23.326 & 5.300 & -.001 & -.700 \\
\hline PR & 503 & 18.634 & 4.879 & & \\
\hline TOTAL & 503 & & & & \\
\hline
\end{tabular}

SMAT: Total score of social media addiction; SMAVT: Social media addiction virtual tolerance; SMAVC: Social media addiction virtual communication; PSSF: Perceived social support from family; PSSSP Perceived social support from a special person; PSSFR Perceived social support from friends; PR: Psychological resilience

Arithmetic means, standard deviations and skewness and kurtosis values of virtual tolerance and virtual communication subscales of social media addiction, perceived social support from family, perceived social support from a special person and perceived social support from friends, and psychological resilience are provided in Table 1. As the skewness and kurtosis values were within + 2 and -2 , it can be said that the data are normally distributed [50].

\subsection{Findings on the First Research Question}

The relationship between social media addiction and perceived social support and psychological resilience was reviewed in accordance with the first research question, and the results are given in Table 2 .

Table 2. Relationship between social media addiction and perceived social support and psychological resilience

\begin{tabular}{|c|c|c|c|c|c|}
\hline Variables & SMA & PSSFR & PSSSP & PSSF & PR \\
\hline SMA & 1 & $-.121 * *$ & $-.096^{*}$ & $-.147 * *$ & $-.190^{* *}$ \\
\hline
\end{tabular}

$* \mathrm{p}<.05 . * * \mathrm{p}<.010$ SMA: Social media addiction; PSSF Perceived social support from family; PSSSP Perceived social support from a special person; PSSFR Perceived social support from friends; PR: Psychological resilience

According to Table 2, social media addiction was found negatively related to perceived social support from family, perceived social support from a special person and perceived social support from friends and psychological resilience. This shows that individuals with high-level perceived social support from family, perceived social support from a special person and perceived social support from friends have lower levels of social media addiction.

\subsection{Findings on the Second Research Question}

Whether social media addiction was predicted by perceived social support and psychological resilience was analyzed with hierarchic regression, and the results are shown in Table 3.
Table 3. Social Media Addiction Hierarchic Regression Analysis

\begin{tabular}{|c|c|c|c|c|c|}
\hline Predictor & $\mathrm{B}$ & $\mathrm{SE}$ & $\beta$ & $\mathrm{t}$ & $\mathrm{P}$ \\
\hline \multicolumn{5}{|c|}{ Block $1: \mathrm{R}^{2}=.027 ; \Delta \mathrm{R}^{2}=.027 ; \mathrm{F}_{(3,499)}=4.596 ; \mathrm{p}<.01$} \\
\hline PSSFR & -.089 & .123 & -.040 & -.722 & .470 \\
\hline PSSF & $\mathbf{- . 2 4 3}$ & $\mathbf{. 1 1 9}$ &.$- \mathbf{1 1 1}$ & $\mathbf{- 2 , 0 3 7}$ & $\mathbf{. 0 4 2}$ \\
\hline PSSSP & -.079 & .061 & -.060 & $-1,302$ & .194 \\
\hline \multicolumn{5}{|c|}{ Block 2: $\mathrm{R}^{2}=.052 ; \Delta \mathrm{R}^{2}=.025 ; \mathrm{F}_{(4,498)}=6.792 ; \mathrm{p}<.001$} \\
\hline PSSFR & -.062 & .122 & -.028 & -.505 & .614 \\
\hline PSSF & -.169 & .120 & -.077 & -1.409 & .160 \\
\hline PSSSP & -.084 & .060 & -.063 & -1.390 & .165 \\
\hline PR & $\mathbf{- . 3 8 9}$ & $\mathbf{. 1 0 8}$ &.- .163 & $\mathbf{- 3 . 6 1 2}$ & $\mathbf{. 0 0 0}$ \\
\hline
\end{tabular}

SMA: Social media addiction; PSSF Perceived social support from family; PSSSP Perceived social support from a special person; PSSFR Perceived social support from friends; PR: Psychological resilience *DurbinWatson $=1.879, * *$ Tolerance values vary between .634 and $.935 . * * \mathrm{VIF}$ values vary between 1.069 and 1.577 .

*As Durbin-Watson value is about 2, it can be said that there was no autocorrelation.

**As tolerance values are above .20 and VIF values below 5 , it can be said that there was no linear relationship between the independent variables.

As seen in the hierarchic regression results in Table 3, perceived social support from family, perceived social support from a special person and perceived social support from friends were included in the block 1 as the predictors of social media addiction. The variables in the block 1 were found significant predictors of social media addiction $\left(\mathrm{F}_{(3,499)}=4.596, \quad \mathrm{p}<.01, \quad \Delta \mathrm{R}^{2}=.027\right) . \quad$ Psychological resilience was included in the block 1 as the predictor of social media addiction, and it was found to be predicting social media addiction significantly $\left(\mathrm{F}_{(4,498)}=6.792, \mathrm{p}<.01\right.$, $\left.\Delta \mathrm{R}^{2}=.025\right)$. It is seen that perceived social support and psychological resilience had a significant effect on social media addiction. It was also determined that perceived social support and psychological resilience together explained $5.2 \%$ of the total variance $\left(\mathrm{R}^{2}=.052 ; \mathrm{F}_{(4,498)}=\right.$ $6.792 ; \mathrm{p}<.001)$.

\section{Discussion and Conclusions}

The relationship between social media addiction and 
perceived social support and psychological resilience among university students was investigated in this research. It was also investigated whether perceived social support and psychological resilience predicted social media addiction. In the research, social media addiction was found related to perceived social support and psychological resilience, and perceived social support and psychological resilience predicted social media addiction.

The first research question was whether there was a relationship between perceived social support and psychological resilience and social media addiction. A low and negative relationship was found between perceived social support from family, perceived social support from a special person and perceived social support from friends, subscales of the perceived social support scale and social media addiction. No study directly investigated perceived social support and social media addiction was not observed in the literature. However, Doğan and Karakuş [8] found a positive relationship between social media addiction and loneliness. In the study conducted by Iş̧1 and Topbaş [13], a negative relationship was found between personal relations with the surroundings and social media addiction. Oktan [27] similarly observed a negative relationship between perceived social support and Internet addiction. These findings coincide with the finding of this study. In other words, it can be said that individuals who have limited interpersonal relations and cannot find the need support in the real-life resort to social media to meet these needs, which causes the addictive behavior.

It was also found in the research that social media addiction was negatively related to psychological resilience. No studies addressing the relationship between social media addiction and psychological resilience were observed in the literature. Given that psychological resilience is the ability to overcome negative life events and adapt to the new situation [31] and social media addiction is a negative situation, one can have a clearer understanding of the relationship between social media addiction and psychological resilience. It can be assumed that individuals who are able to cope with negative experiences and adapt to the new situation do not feel the need to search for any shelter (social media) due to these negative experiences, and therefore the addictive behavior does not develop among individuals.

The other research question is whether perceived social support and psychological resilience predicted social media addiction. It was found that only the perceived social support from friends' subscale of the perceived social support scale predicted social media addiction significantly and negatively, and perceived social support from family and perceived social support from a special person did not predict social media addiction significantly. No study examining perceived social support's effect on social media addiction was observed in the literature. Yet, the relationship between social media addiction and concepts such as loneliness and personal relations that are associated with perceived social support (Y1lmaz et al., [25]; Duru,[26]; Doğan and Karakuş, [8]; Işık \& Topbaş, [13]) give us an opinion on perceived social support's effect on social media addiction. What can be inferred from this finding is that as the social support received by individuals from their social friends in real life decreases, they start to search friends on social media, and the addictive behavior emerges as a consequence of this search.

It was found that psychological resilience predicted social media addiction significantly and negatively. No research examining psychological resilience's effect on social media addiction was observed in the literature. The positive relationship between psychological resilience and negative concepts and situations such as social connected ness and recognition about belonging, forgiveness of self, others, and situations, satisfaction with life, optimism and psychological well-being, happiness, positive self-schema, emotional intelligence, and self-esteem (Arslan, [37]; Karaırmak and Güloğlu [38]; Eraslan Çapan \& Arıcıoğlu [39]; Ülker Tümlü \& Recepoğlu [40]; Souri \& Hasanirad [41]; Doğan [31]; Basım \& Çetin [42]; Özer \& Deniz [43]; Kararrmak \& Siviş-Çetinkaya [44]) and the positive relationship between social media addiction and negative concepts and situations such as emotional problems, anxiety, Facebook gaming addiction, and narcissism (Doğan \& Karakuş [8]; Tutgun-Ünal [4]; Correa, Hinsley and Zuniga [9]; Al Kord [10]; Koşan [11]) make the negative relationship between these two concepts more understandable. It can be inferred from this finding of the research that individuals behave more healthily when they are psychologically resilient, that is, can cope with negative experiences and use their adaptation skills in the face of problematic experience and social media addiction, which is an unhealthy coping strategy, does not emerge.

When handling the research results as a whole, it can be said that perceived social support and psychological resilience are effective on social media addiction. It can be therefore assumed that increase in perceived social support and psychological resilience is effective in a decrease in social social media addiction and lack of both concepts increases social media addiction.

\section{Recommendations}

Some recommendations were made for those who study for practical purposes in the field.

Experts can carry out studies to increase social support for social media addicts in consideration of the negative relationship between perceived social support and social media addiction.

Addicts can be encouraged to make social friends in real life. To this end, they can be canalized towards social activities, cultural and artistic activities and sportive activities.

Experts can inform the families of social media addicts 
of how social support affects social media addiction, therefore guiding them about taking the necessary precautions.

Studies for enhancing individuals' psychological resilience (psychoeducational, workshop studies) can prevent social media addiction.

The recommendations for researchers regarding the future studies in accordance with the research results are as follows:

This research is limited to 503 university students in the sample. The research results can be tested in studies to be conducted at different universities.

This research was carried out only with university students. The same study can be performed with adolescents and adults, and results can be compared.

Social media addiction draws attention as a phenomenon which is increasingly becoming common. Yet, there is insufficient number of studies on the matter. In different research studies, relationships between social media addiction and other concepts that can be associated with it.

\section{Declaration of Conflicting Interests}

The author(s) declared no potential conflicts of interest with respect to the research, authorship, and /or publication of this article.

\section{Funding}

The author(s) received no financial support for the research and/or authorship of this article

\section{REFERENCES}

[1] Boyd, D. M., \& Ellison, N. B. (2008). Social Network Sites: Definition, history and scholarship. Journal of Computer-Mediated Communication. 13, 210-230. Doi:10.1111/j.1083-6101.2007.00393.x.

[2] Kuss, D. J., \& Griffiths, M. D. (2011). Online social networking and addiction- a review of the psychological literature. Int. J. Environ. Res. Public Health, 8, 3528-3552. Doi:10.3390/ijerph8093528.

[3] O'Keeffe, G. S., \& Clarke-Pearson, K. (2011). Clinical Report- The impact of social media on children, adolescents, and families. Retrieved from

http://pediatrics.aappublications.org/content/127/4/800-804.

[4] Tutgun-Ünal, A. (2015). Social media addiction: A research on university students. (Doctoral Dissertation, University of Marmara, Istanbul, Turkey). Retrieved from https://tez.yok.gov.tr

[5] Van den Eijnden, R. J. J. M., Lemmens, J. S., \& Valkenburg, P. M. (2016). The social media disorder scale. Computer in Human Behavior 61, 478-487. http://dx.doi.org/10.1016/j.chb.2016.03.038.

[6] Andreassen, C. S., Torsheim, T., Brunborg, G. S., \& Pallesen, S. (2012). Development of a Facebook addiction scale. Psychological Reports, 110( 2), 501-517. Retrieved from

https://www.researchgate.net/publication/225185226_Deve lopment_of_a_Facebook_Addiction_Scale. Doi:10.2466/02.09.18.

[7] Tektaş, N. (2014). A research on university students' social networking habits. Journal of History School (JOHS), 7(18). 851-870. Doi: http://dx.doi.org./10.14225/Joh474.

[8] Doğan, U., \& Karakuş, Y. (2016). Multi-dimensional loneliness as the predictor of high school students' social network sites (SNS) use. Sakarya University Journal of Education, 6(1), 57-71.

Doi:http://dx.doi.org./10.19126/suje.40198.

[9] Correa, T., Hinsley, A. W., \& Zuniga, H. G. (2010). Who interacts on the Web_ The intersection of users' personality and social media use. Computer in Human Behavior, 26, 247-253. doi:10.1016/j.chb.2009.09.003

[10] Al Kord, N. Y. M. (2016). Determination of demografic factors affecting game addiction on facebook environment. (Master's Thesis, University of Gazi, Ankara, Turkey). Retrieved from https://tez.yok.gov.tr.

[11] Koşan, Y. (2015). Investigation of the relationship of the university students using Facebook with narcissism and aggression levels. (Master's Thesis, University of Yüzüncü Y1l University, Van, Turkey). Retrieved from https://tez.yok.gov.tr.

[12] Çam, E. (2012). Educational and general use of facebook and Facebook addiction of teacher candidates (SAU College of education sample). (Master's Thesis, University of Sakarya University, Sakarya, Turkey). Retrieved from https://tez.yok.gov.tr.

[13] Işık, U., \& Topbaş, H. (2015). Facebook and dependency: Research of media system dependency. International Journal of Social Science. 38. 319-336. Doi: http://dx.doi.org/10.9761/JASSS2930.

[14] Mutlu, Ş. (2014). Examining the high school students' self-respect and desolation levels according ti frequency of using social sharing website Facebook and some applications of this site. (Master's Thesis, University of Yüzüncü Y1l University, Van, Turkey). Retrieved from https://tez.yok.gov.tr.

[15] Budak, S. (2003). Psychology Dictionary (2. Baskı). Ankara: Bilim ve Sanat

[16] Bal, S., Crombez, G., Van Oost, P., \& Debourdeaudhuij, I. (2003). The role of social support in well-being and coping with self-reported stressful events in adolescents. Child Abuse \& Neglect, 27, 1377-1395.

[17] Vedder, P., Boekaerts, M., \& Seegers, G. (2005). Perceived social support and well-being in school; the role of student ethnicity. Journal of Youth and Adolescence, 34(3), 269-278.

[18] Yıldırım, İ. (1997). Development of perceived social support scale: A validity and reliability study. H.U Education Faculty Journal. 13. 81-87. 
[19] Eşkisu, M. (2009). Investigation of the relationship between the bullying grade, family functions and perceived social support among high school students. (Master's Thesis, University of Istanbul University, Istanbul, Turkey). Retrieved from https://tez.yok.gov.tr.

[20] Eker, D., Arkar, H., \& Yaldı, H. (2001). Factorial structure, validity, and reliability of revised form of the multidimensional scale of perceived social support. Turkish Journal of Psychiatry, 12(1), 17-25.

[21] Malkoç, A., \& Yalçın, İ. (2015). Relationship among resilience, social support, coping, and psychological wellbeing among university students. Turkish Psychological Counseling and Guidance Journal, 5(43), 35-43.

[22] Aydın, A., Kahraman, N., \& Hiçdurmaz, D. (2017). Determining the levels of perceived social support and psychological well-being of nursing students. Journal of Psychiatric Nursing, 8(1), 40-47.

[23] Türkdoğan, T. (2017). The relationship between university students' retrospectively perceptions of parental acceptance-rejection about childhood and their psychological adjustments in adulthood. Turkish Psychological Counseling and Guidance Journal, 7(47), 135-154.

[24] Çivitci, A. (2015). Self-esteem and social supportas predictors of trait anger: mediating and moderating roles of social support. Abant İzet Baysal University Journal of Education Faculty, 15(1), 66-81.

[25] Y1lmaz, E., Y1lmaz, \& Karaca, F. (2008). Examining the level of social support and loneliness of university students. General Medical Journal, 18(2), 71-79.

[26] Duru, E. (2008). The direct and indirect roles of social support and social cohesion as a predictor of loneliness in the process of adaptation to the university. Turkish Psychological Counseling and Guidance Journal, 3(29), 13-24.

[27] Oktan, V. (2015). Problematic internet use, loneliness and perceived social support among university students. Kastamonu Education Journal, 23(1), 281-292.

[28] Firat, N., \& Kaya, F. (2015). An examination of social support level and stress coping strategies of students staying at home or in dormitory. Turkish Studies, 10(7). 407-426. DOI Number: http://dx.doi.org/10.7827/TurkishStudies.8140, ANKARA-TURKEY.

[29] Holt, M. K., \& Espelage, D. L. (2007). Perceived social support among bullies, victims, and bully-victims. J. Youth Adolescence, 36, 984-994.

[30] Çeçen, A. R. (2008). Examination of levels of loneliness and social support according to gender and parental attitudes of university students. Journal of Turkish Educational Sciences, $6(3), 415-431$.

[31] Demirtaş, A. S. (2007). The relationship between perceived social support, loneliness and the coping stress levels of the students attending the 8th class in elementary schools. (Master's Thesis, University of Gazi University, Ankara, Turkey). Retrieved from https://tez.yok.gov.tr.

[32] Herrman, H., Stewart, D. E., Granados, N. D., Berger, E. L.,
Jackson, B., \& Yuen, T. (2011). What is Resilience? Can. J. Psychiatri, 56(5), 258-265.

[33] Doğan, T. (2015). Adaptation of the brief resilience scale into Turkish: A validity and reliability study. The Journal of Happiness \& Well-Being, 3(1), 93-102.

[34] Block, J., \& Kremen, A. M. (1996). IQ and ego-resiliency: Conceptual and empirical connections and separateness. Journal of Personality and Social Psychology, 70(2), 349-361.

[35] Rutter, M. (2006). Implications of resilience concepts for scientific understanding. Annals New York Academy of Sciences, 1094, 1-12. Doi: 10.1196/annals.1376.002

[36] Kaba, İ., \& Keklik, İ. (2016). Students' adaptation to university life, resilience and psychological symptoms. The Journal of Educational Research, 2(2), 98-113.

[37] Arslan, G. (2015). The relationship between psychological maltreatment, resilience, social connectedness, and belongingness. Mehmet Akif Ersoy University Journal of Education Faculty, 36, 47-58.

[38] Kararrmak, Ö., \& Güloğlu, B. (2014). The explanation of resilience within attachment model among adults with earthquake experience. Ç.U Journal of Education Faculty. 43(2), 01-08. Doi: 10.14812/cufej.2014.010.

[39] Eraslan Çapan, B., \& Arıcıoğlu, A. (2014). Forgiveness as predictor of psychological resiliency. e International Journal of Educational Research, 5(4), 70-82.

[40] Ülker Tümlü, G., \& Recepoğlu, E. (2013). The relationship between psychological resilience and life satisfaction of university academic staff. Journal of Higher Education and Science, 3(3), 205-213. Doi: 10.5961/jhes.2013.078.

[41] Souri, H., \& Hasanirad, T. (2011). Relationship between resilience, optimism and psychological well-being in students of medicine. Social and Behavioral Sciences, 30(2011), 1541-1544.

[42] Basım, H. N., \& Çetin, F. (2011). The reliability and validity of the resilience scale for adults Turkish version. Turkish Journal of Psychiatry, 22(2), 104-114.

[43] Özer, E., \& Deniz, M. E. (2014). An investigation of university students' resilience level on the view of trait emotional. Elementary Education Online, 13(4), 1240-1248. DOI: $10.17051 /$ io. 2014.74855 .

[44] Karaırmak, Ö., \& Siviş-Çetinkaya, R. (2011). The effect of self-esteem and locus of control on resilience: The mediating role of affects. Turkish Psychological Counseling and Guidance Journal, 4(35), 30-43.

[45] Pietrzak, R. H., Johnson, D. C., Goldstein, M. B., Malley, J. C., \& Southwick, S. M. (2009). Psychological resilience and post deployment social support protect against traumatic stress and depressive symptoms in soldiers returning from operations enduring freedom and Iraqi freedom. Depression and Anxiety, 0, 1-7.

[46] Lee, E-K. O., Shen, C., \& Tran, T. V. (2009). Coping With Hurricane Katrina: Psychological Distress and Resilience among African American Evacuees. Journal of Black Psychology, 35(1), 5-23. doi:10.1177/0095798408323354. 
[47] Büyüköztürk, Ş., Kılıç, Çakmak, E., Akgün, Ö.E., Karadeniz, Ş. \& Demirel, F. (2010). Bilimsel araştırma yöntemleri. Ankara: Pegem Akademi.

[48] Şahin, C., \& Yağc1, M. (2017). Social media addiction scale-adult form: The reliability and validity study. KEFAD, 18(1), 523-538.
[49] Zimmet, G. D., Powel, S. S., Farley, G. K. et al. (1988). Psychometric characteristics of the multidimensional scale of perceived social support. J. Pers Assess, 55, 610-617.

[50] Kalaycı, Ş. (2014). Spss applied multivariate statistical techniques. Asil: Ankara 